\title{
Local Management of Tuberculosis by Traditional Medicine Practitioners in Lake Victoria Region
}

\author{
John A. Orodho ${ }^{*}, 1$, Claude Kirimuhuzya ${ }^{*}, 2$, Joseph N. Otieno ${ }^{3}$, Joseph J. Magadula ${ }^{3}$ and \\ Paul Okemo ${ }^{4}$
}

\author{
${ }^{1}$ Policy and Curriculum Studies, School of Educational Management, Kenyatta University, P.O. Box 43844-00100, \\ Nairobi, Kenya \\ ${ }^{2}$ Department of Pharmacology and Therapeutics, Faculty of Medicine, Makerere University, P.O. Box 7072, Kampala, \\ Uganda \\ ${ }^{3}$ Institute of Traditional Medicine, Muhimbili University, P.O. Box 65001, Dares Salaam, Tanzania \\ ${ }^{4}$ Plant and Microbial Science, School of Pure and Applied Science, Policy and Curriculum Studies, Kenyatta University, \\ P.O. Box 43844-00100, Nairobi, Kenya
}

\begin{abstract}
Tuberculosis (TB) is now a global public health problem that has been exacerbated by the emergence of multiand extensively-drug resistant (MDR and XDR, respectively) strains of Mycobacterium tuberculosis. There have been claims in the region by Traditional Medicine Practitioners (TMPs) about being able to treat the symptoms of TB, but their work lacked proper documentation. A structured questionnaire was used to test the ability of (TMPs) to diagnose and treat symptoms of TB; the medicinal plants used treat TB symptoms, as well as the influence of socio-economic and cultural factors on the indigenous communities' choice of treatment. A total of 99 TMPs and 22 TB patients were interviewed. Over 30 medicinal plants were mentioned as being used to treat symptoms of TB, an indication of wide knowledge on management of TB in the region. Treatment costs were found to influence the patients' choice of TB treatment and a large proportion of the TMPs were found to be of advanced age (60-80 years of age). The conclusion was that TMPs have reasonable knowledge about TB and its management. There is urgent need to tap the indigenous knowledge from the custodians and scientifically validate it for future drug development.
\end{abstract}

Keywords: Multi-drug resistant tuberculosis, extensively drug resistant tuberculosis, traditional medicine practitioners, socioeconomic and cultural factors, Lake Victoria Region.

\section{INTRODUCTION}

Tuberculosis (TB) is now a global public health problem that has been exacerbated by the emergence of multi-drug resistant (MDR) and extensively drug resistant (XDR) strains of Mycobacterium tuberculosis. One third of the world's population has TB and it is responsible for approximately three million deaths each year [1]. It is also estimated that eight million new cases of TB occur each year and Africa has the highest incidence rate [2]. Sub-Saharan Africa has the highest rate among the African states [3]. At the regional podium, Uganda has a prevalence rate of 65 percent, with Kenya and Tanzania at around 57 percent [4]. There is little contest that these figures portray the Lake Victoria region as a tuberculosis endemic zone.

Furthermore, recent statistics indicate that women are more affected by TB than men. Tuberculosis is, therefore, a

\footnotetext{
*Address correspondence to these authors at the Department of Pharmacology and Therapeutics, Makerere University College of Health Sciences, P.O. Box 7062, Kampala, Uganda; Tel: +256 41 533332945; Fax: +256 41532947; Mobile: +256 772645 991; E-mail: claudekirim@yahoo.co.uk and Educational Management, Policy and Curriculum Studies, School of Education, Kenyatta University, P.O. Box 43844-00100, Nairobi, Kenya; Cell: +254-721239165; E-mail: orodhojohn@gmail.com
}

serious problem in the region which, if not urgently addressed is threatening to wipe out the gains made in various areas of development including agriculture, education, commerce, and science and technology. The situation has particularly been aggravated by the emergence of multi-drugresistant tuberculosis (MDR TB), for which the treatment with second-line drugs is beyond the reach of most communities in African countries [1,5].

Tuberculosis management is largely by chemotherapy involving a complex regimen of five drugs used in combinations, and treatment can go up to 8 months and is punctuated with serious side effects. The Directly Observed Therapy, Shot Course (DOTS) strategy, which was put forward by WHO for the management of TB to ensure compliance and counter the development of resistance against existing drugs seems to be failing, if we consider the prevalence of MDR TB and emergence of extensively drug resistant tuberculosis (XDR TB) strains. The XDR TB, which is resistant to both the first and second-line drugs, is threatening to make TB impossible to treat especially in cases of co-infection with HIV/AIDS [6-9].

For MDR TB, the treatment requires the use of second line drugs, which are more expensive, and with even more serious adverse effects. This has led to high levels of noncompliance from patients and could be responsible for the 
emergence of XDR TB strains. Furthermore, reported drug interactions between anti-TB drugs, especially rifampicin, with some antiretroviral drugs (ARVS), have complicated the management of TB in HIV-positive patients [10].

To mitigate the shortcomings of allopathic medicine in this situation, a large percentage of patients in the African Region, and East Africa in particular, seek remedy from traditional medical practitioners (TMPs) who use crude preparations of medicinal plants. In this region there have been claims of Traditional Medicine Practitioners (TMPs) being able to treat the symptoms of TB but there has been a large knowledge gap with regard to the documentation of the species of the medicinal plants used by the TMPs in treating the symptoms of tuberculosis. There has been a need for proper documentation and scientific validation of the TMPs. Therefore, basing on the fact that the elderly usually possess this knowledge, it was vital that surveys to document such plant species be carried out. It was in response to such a need that our team set out to carry out an ethnobotanical survey to document the medicinal plant species used by indigenous communities in the Lake Victoria region, the cases of TB patients treated and the socio-economic implications of such methods of managing TB. This would then be followed by laboratory screening of extracts from the medicinal plants for biological activity to scientifically validate the ethnobotanical claims.

\section{METHODS}

\section{Research Design}

The study adopted an ethnobotanical approach using a carefully designed questionnaire to capture the ability of the indigenous communities to diagnose and treat symptoms of TB; the medicinal plants used to treat TB symptoms; and the influence of cost implications on patients' choice of treatment for tuberculosis. We targeted traditional medicine practitioners (TMPs) in the Lake Victoria region to represent the informed specialists in the use of herbal medicine as well as the TB patients who had been the beneficiaries of TMPs.

\section{Study Sites and Period}

The study was performed over a period of eight months from March to October 2007 among various ethnic communities in the three East African Countries which included Teso, Siaya/Bondo, and Kisii Districts in Kenya; Mukono, Mayuge, and Mbarara Districts in Uganda; and Musoma, Bunda, Magu, Geita and Sangerema Districts in Tanzania. These districts were selected purposively using the criteria of high prevalence rate of TB infections, ethnic diversity of residents and the fact that the areas were known to have many TMPs.

District officials and community development Officers were used to identify guides and TMPs to be interviewed. The patients were identified through the TMPs. The study used a combination of purposive and snowball/network sampling techniques to reach 32 TMPs in Kenya, 31 in Uganda and 39 in Tanzania; making a sample of 99 TMPs. In addition, the study reached 3 TB patients in Kenya, 3 in Tanzania and 16 in Uganda, making a total sample size of 22 TB patients for the study.

\section{Research Instruments and Socio-Economic Data}

In this study observations were made on both TMPs' actual behavior during the management of tuberculosis as well as on indicators of appropriate use of herbal medicine and diagnosis of TB. This included capturing information on types of materials used, methods of preparation and administration of medicinal preparations used in the treatment of symptoms of TB.

\section{Data Analysis}

Data from the questionnaires were entered into a computer using Epi-Data software programme in readiness for analysis using the Statistical Package for Social Sciences (SPSS) for windows version 11.5. Descriptive statistics using frequencies and cross-tabulations were utilized in constructing tables showing the commonly used plant species by country and district, knowledge of plant species by age and gender, knowledge of signs of TB by age and educational level, knowledge of causes of TB by district, age and sex, and the cost of treating TB by country and district.

The Pearsons' Product Moment Correlation (r), the Chisquare ( $\chi 2$ ), Analysis of Variance (ANOVA) and Regression statistical techniques were used to test the null hypotheses. A stepwise Multiple Regression Statistical technique was used to test the contribution of various factors (independent variables) to test the level of knowledge of the plant species used to treat TB, knowledge of signs of TB; causes of TB; and cost of treating TB (the dependent variables).

\section{Dependent Variables}

The main dependent variables for the study were:

1. Level of knowledge of plant species used to treat tuberculosis (measured in terms of ability to identify the plant species by local names and the type of concoctions made).

2. Knowledge of the major symptoms or signs of TB. These were compared with the medically known critical signs such as: (i) persistent cough for over three weeks; (ii) night sweats; (iii) fever; (iv) loss of $10 \%$ or more of body weight; (v) HIV infection or medical history of the patient seeking TMP treatment [1].

3. Knowledge of some causes of TB. These were to be compared with other known causes such as: bacterial infection, overcrowding/contacts, contamination, and smoking among other causes.

4. The cost of treating TB. The range of these charges were given in local currencies in each country and later converted into US Dollars for ease of comparison.

\section{Independent Variables}

The socio-economic/ demographic variables of interest to this study were:

1. Sex of TMP and TB patient.

2. Age of TMP and TB patient.

3. Level of highest educational attainment by TMPs.

4. Occupational status of TMPs. 
5. Country of residence TMPs (Kenya, Uganda and Tanzania).

6. District/ethnicity of TMPs (Kisii in Kisii District; Luo in Siaya/Bondo; and Ateso in Teso District in Kenya; Basoga in Mayuge; Baganda in Mukono; and Banyankole in Mbarara Districts in Uganda; and Sukuma in Geita, Sangerema and Bunda Districts; Mkelewe in Geita, Mruri in Magu and Luo and Ikizo in Musoma Districts of Tanzania).

To examine the relationship between, for example, knowledge of medicinal plant species used selected socioeconomic variables such as age, sex, occupational status and country/district or ethnicity, a simple regression model was used in the form:

$$
\mathrm{Y}=\mathrm{a}+\mathrm{bX}+\mathrm{e}
$$

Where, $Y=$ level of knowledge of medicinal plant species

$\mathrm{X}=$ age of TMP

$\mathrm{b}=$ partial regression coefficient

$\mathrm{a}=$ the $\mathrm{y}$-intercept

$\mathrm{e}=$ error term (the unexplained variance).

For further interpretation, the error term was assessed in relation to the data collected from ethnographic, observation schedules and perceived determinants on the part of the respondent [11]. The Multiple Regression Models incorporated more than one independent variable to explain the variation on the dependent variable [25]. form:

In this study, the Multiple Regression mode took the

$$
\mathrm{Y}_{1}=\mathrm{a}+\mathrm{b}_{1} \mathrm{X}_{1}+\mathrm{b}_{2} \mathrm{X}_{2}+\mathrm{b}_{3} \mathrm{X}_{3}+\ldots \ldots \ldots+\mathrm{b}_{\mathrm{n}} \mathrm{X}_{\mathrm{n}}+\mathrm{e}
$$

Where, $Y_{1}=$ the knowledge of medicinal plants used to treat TB

$\mathrm{X}_{1}=$ Age of TMp

$\mathrm{X}_{2}=$ Sex of TMP

$\mathrm{X}_{3}=$ Other occupation of TMP

$\mathrm{X}_{4}=$ Country or district

$X_{n}=$ Other variables of interest to the study

$\mathrm{a}=$ intercept

$b_{1}, b_{2}, b_{3}, b_{4}, \ldots b_{n}=$ Partial regression coefficients

$\mathrm{e}=$ error term.
The bivariate correlation coefficient was first computed to establish the nature and degree of relationship between the variable. A step-wise Multiple Regression was used to determine the independent variable that had a greater causal effect on the dependent variable. As a result, the isolated variable was retained in the regression equation. This procedure isolated and eliminated those independent variables that had little casual effect on the dependent variables i.e.

$\mathrm{Y}_{1}=$ Level of knowledge of medicinal plants used to treat TB

$\mathrm{Y}_{2}=$ The level of knowledge of signs or symptoms of TB

$\mathrm{Y}_{3}=$ The level of knowledge of possible cause of TB

$\mathrm{Y}_{4}=$ The charges or cost of treating TB in US \$.

\section{Ethical Considerations}

The purpose of the study and how the information would be utilized to protect the interests of the respondents was explained and verbal consent got before the commencement of the data collection exercise. Ethical approval was obtained from the relevant authorities in countries in which the study was carried out.

\section{RESULTS}

\section{TMPs and TB Patients}

A total of 99 TMPs were interviewed; 32 being in Kenya, 31 in Uganda and 39 in Tanzania. In addition, the study reached 3 TB patients in Kenya, 3 in Tanzania and 16 in Uganda, making a total of 22 TB patients. The second step was to find estimate the prevalence of TB infections in East Africa by asking the TMPs to estimate the numbers of patients seeking treatment from them per day. Table 1 portrays the grouped frequencies of TB patients seeking TMPs treatment.

The data carried Table 1 reveal the overall message that the number of people seeking treatment for TB is quite high in the Lake Victoria region.

\section{TMPs' Knowledge about TB}

The following were the most frequently mentioned signs of TB across the region:

Table 1. Number of TB Patients Treated by TMPs Per Day in Lake Victoria Region

\begin{tabular}{|c|c|c|c|c|}
\hline Number & Kenya (\%) & Tanzania (\%) & Uganda (\%) & Total (\%) \\
\hline \hline None & 3.0 & 4.0 & 0.0 & 4.0 \\
\hline $1-3$ & 3.0 & 27.1 & 9.1 & 21.2 \\
\hline $4-6$ & 6.1 & 6.1 & 3.1 & 8.1 \\
\hline $7-9$ & 5.1 & 0.0 & 3.0 & 8.1 \\
\hline $10-12$ & 5.1 & 1.0 & 4.0 & 12.1 \\
\hline $13-15$ & 8.1 & 0.0 & 2.0 & $\mathbf{2 9 . 3}$ \\
\hline 16 and above & 4.0 & 1.0 & $\mathbf{3 9 . 4}$ & $\mathbf{1 0 0 . 0}$ \\
\hline Total & $\mathbf{3 1 . 3}$ & & & \\
\hline
\end{tabular}


(a) Dry lips: $24.2 \%$, (Kenya $3.0 \%$, Tanzania $20.2 \%$ and Uganda1.0\%).

(b) Coughing sputum: $17.2 \%$ (Kenya $1.0 \%$, Tanzania $13.1 \%$ and Uganda 3.0\%).

(c) Persistent dry cough: $11.1 \%$ (Kenya 3.0\%, Tanzania $1.0 \%$ and Uganda $7.1 \%$ ).

(d) Loss of body weight and tiredness: $70.1 \%$ (Kenya $7.1 \%$, Uganda $3.0 \%$ ).

(e) Medical diagnosis: 9.1\% (Kenya 2.0\%, Uganda $7.1 \%$ ).

(f) Labored breathing /shortness of breath: 7.1\% (Kenya $5.1 \%$, Uganda $2.0 \%$ ).

(g) Coughing blood: $5.1 \%$ (Kenya $3.0 \%$, Tanzania $2.0 \%$ ).

(h) Night fevers, loss of appetite, chest pains and night sweats: about $4.0 \%$.

It was also evident that a good proportion of the communities in all the three East African countries had a good idea about the causes of tuberculosis. The causes, which were cited with higher frequencies of mention, in descending order of magnitude were:

(a) Droplet air-borne infection: $20.2 \%$ (Kenya 2.0\%, Tanzania $11.1 \%$ and Uganda $7.1 \%$ )

(b) Germs by contact: $15.2 \%$ (Kenya $2.0 \%$, Tanzania Nil, Uganda $13.1 \%$ ).

(c) Smoking: 14.1\% (Kenya 6.1\%, Tanzania $2.0 \%$ and Uganda $6.1 \%$ ).

(d) Alcoholism and lung complications: 10.1\% (Kenya 7.1\%, Tanzania $1.1 \%$ and Uganda $2.0 \%$ ).

\section{Influence of Treatment Charges}

In terms of charges for the treatment by the TMPs, it was established that a majority of the TMPs, constituting about $28.3 \%(3.0 \%$ in Kenya $14.1 \%$ in Tanzania and $11.0 \%$ in Uganda) charge their TB patients between US \$ 1-10. The next larger proportion of TMPs, $17.2 \%$ (Kenya 6.1\%, Tanzania $5.1 \%$ and Uganda $6.1 \%$ ) charged US\$ $11-20$ for the treatment of TB. A further $12.1 \%$ (Kenya $6.1 \%$, Tanzania 2.05 and Uganda 4.0\%) charge US\$ 51-60. It was also surprising to note that about $16.2 \%$ (Kenya $2.0 \%$ and Tanzania $14.1 \%$ ) did not charge any fee but left it to the discretion of the patient to pay on recovery. It was established that there was a moderately strong correlation between the charges levied by the TMPs for the treatment of $\mathrm{TB}$ and the country/ district of residence $(\mathrm{r}=0.35, \mathrm{P} \leq 0.001)$, with Tanzania charging the least. There was a very weak (almost no correlation) between sex and age of TMPs and their charges for treatment.

There was a moderate correlation between the average charges for the treatment of TB and how the TMPs acquired their knowledge $(\mathrm{r}=0.25, \mathrm{P} \leq 0.05)$. The TMPs who had acquired their skills through their parents and grand parents charged lesser amount compared to those who acquired their skills through either healers or through other sources (books and seminars). Responses on how TMPs assessed the recovery of their TB patients after undergoing treatment are summarized in Table $\mathbf{2}$.

The results show that about two-thirds of TMPs learnt about the recovery of their TB patients either through selfreporting or through other TB patients referred to them by those who had recovered from after treatment. Most of the patients who reported that they got to know their recovery status through laboratory testing were from Uganda. None of the TB patients from Tanzania reported that they had undergone laboratory testing.

\section{Medicinal Plants Used to Treat TB}

The study established that there was a wide range of plant species being used to treat tuberculosis in Lake Victoria region. All the mentioned plant species were identified by competent taxonomists and voucher specimens prepared and deposited with the University herbaria at Kenyatta, Makerere and Muhimbili Universities in Kenya,

Table 2. How Recovery Rate Were Known

\begin{tabular}{|c|c|c|c|c|}
\hline District/Country & Self Reporting / Other Patients (\%) & Lab Tests $(\%)$ & Still on Treatment (\%) & Total (\%) \\
\hline Kisii (Kenya) & 9.0 & 1.1 & 4.5 & 14.6 \\
\hline Teso (Kenya) & 12.4 & 0.0 & 0.0 & 12.4 \\
\hline Mayuge (Uganda) & 2.2 & 3.4 & 6.7 & 12.4 \\
\hline Mukono (Uganda) & 4.5 & 2.2 & 0.0 & 6.7 \\
\hline Musoma (Tanzania) & 6.7 & 0.0 & 0.0 & 6.7 \\
\hline Bunda (Tanzania) & 1.1 & 0.0 & 1.1 & 2.2 \\
\hline Magu (Tanzania) & 9.0 & 0.0 & 1.1 & 10.1 \\
\hline
\end{tabular}


Uganda and Tanzania respectively. Table $\mathbf{4}$ displays the most commonly used species distributed according to frequency of mention. Over 50 plant species were mentioned but only those that were mentioned in at least two countries are indicated. Majority of these species were naturally growing, and few such as Eucalyptus and Psidium guajava were naturalized.

Most of the extracts from the plant species presented in Table 3 were being used in combinations of more than one plant species, or with addition of minerals or animal products. In terms of district/ ethnic distribution, Warbugia ugandensis was widely used in Kenya among the Kisii, in
Kisii District, Luo in Siaya/ Bondo District and Ateso in Teso Districts; Uganda among the communities living in Mayuge and Mbarara; and in Tanzania in Geita Districts. Entada abyssinica was also used in Kenya (Kisii, Siaya and Teso), Tanzania (Musoma and Bunda Districts); and rarely among the communities in Uganda. In Uganda the most commonly used plant species to treat $\mathrm{TB}$ are Rubia cordifolia and Psidium guajava in Mayuge District and Albizia coriaria, Acacia hockii and Garcinia species in Mbarara District. The six most commonly used plant species and their corresponding biologically active chemical constituents that have been studied are indicated in Table 4 .

Table 3. The Plant Species Reportedly Used by TMPs to Treat TB in Lake Victoria Region

\begin{tabular}{|c|c|c|c|c|c|c|c|}
\hline S. No. & Species & Family & Main Part Used & \multicolumn{4}{|c|}{ Frequency } \\
\hline 1 & Entada abyssinica & Fabaceae & Roots & 12 & 13 & 3 & 28 \\
\hline 2 & Albizia versicola & Leguminasae & Leaves & 2 & 2 & & 4 \\
\hline 3 & Balanites aegyptiaca & Balanitaceae & Stem bark & 2 & 2 & & 4 \\
\hline 6 & Croton dichogamus & Euphorbiaceae & Root & 3 & 2 & & 3 \\
\hline 7 & Eucalyptus spp. & Myritaceae & Leaves & 4 & 1 & 3 & 7 \\
\hline 8 & Psidium guajava & Myritaceae & Leaves & 4 & 1 & 3 & 5 \\
\hline 9 & Albizia coriaria & Leguminasae & Stem bark & 1 & & 8 & 9 \\
\hline 12 & Mangifera indica & Anacardaceae & Stem bark & 2 & & 6 & 6 \\
\hline 13 & Zanthoxylum chalybeum & Rutaceae & Root & 1 & 1 & 5 & 5 \\
\hline 14 & Erythrina abyssinica & Papilionacea & Root bark & 1 & 1 & 4 & 4 \\
\hline 15 & Garcinia buchananii & Crusiceae & Root bark & 1 & 1 & 4 & 4 \\
\hline 16 & Solanum incanum & Solanaceae & Fruits & 1 & & 4 & 4 \\
\hline 17 & Cryptolepis sanguinolenta & Periprocaceae & Root & 2 & & 4 & 4 \\
\hline 18 & Dracaena steudneri & Liliaceae & Stem & 1 & & 4 & 4 \\
\hline 19 & Solanum aculeastrum & Solanaceae & Fruit & & & 3 & 3 \\
\hline 26 & Acanthus pubescens & Acanthaceae & Root & 1 & & 1 & 2 \\
\hline 27 & Aloe secundiflora. & Aloaceae & Leaves & 5 & & 1 & 6 \\
\hline 28 & Allium sativum & Alliaceae & Leaves & 3 & & 1 & 4 \\
\hline 29 & Albizia zygia & Leguminosae & Root & 4 & & 1 & 5 \\
\hline 30 & Canarium schweinfurthii & Burseraceae & Root & 1 & & 2 & 3 \\
\hline
\end{tabular}


Table 4. The Six Most Commonly Used Plant Species to Treat TB in Lake Victoria Basin

\begin{tabular}{|c|c|c|c|}
\hline S. No. & Species & Chemical Constituents & References \\
\hline \hline 1 & Entada abyssinica Steud ex A. Rich & Flavonol glycosides, Diterpenes & {$[12]$} \\
\hline 2 & Warbugia ugandensis Sprague & Sesquiterpenes & {$[13,14]$} \\
\hline 3 & Rubia cordifolia Linn. & Alkaloids, cardiac glycosides tannins, flavonoids and phenols & {$[15]$} \\
\hline 4 & Eucalyptus spp. Labill. & Essential oils: eucalyptol, cineole, tannins, saponins, phenols, steroids & {$[16,17]$} \\
\hline 5 & Zanthoxylum chalybeum Engl. & Alkaloids e.g. skiammine & {$[18]$} \\
\hline 6 & Mangifera indica Linn. & Saponins, Tannins, Glycosides, phenols, Mangiferin & {$[19]$} \\
\hline
\end{tabular}

The study established non-significant correlation between the level of knowledge of the plant species used to treat tuberculosis and the age of the TMPs. The implication was that most of this useful knowledge has been passed over to the younger generation. However, it was found that there was significant difference between the level of knowledge of plant species used to treat TB and the sex of the TMPs $\left(\chi^{2}=\right.$ 46.6, $\mathrm{df}=35, \mathrm{P} \leq 0.001)$ and the main occupational status of TMPs $\left(\chi^{2}=42.7, \mathrm{df}=35, \mathrm{P} \leq 0.001\right)$. It was evident that male TMPs had better knowledge than the female counterparts. Furthermore, the TMPs whose main occupation was practicing herbal medicine and/or farming and nursing had better knowledge regarding the medicinal plants used to treat $\mathrm{TB}$, than those with other occupations or businesses. It was further noted that there was a moderately weak correlation between the TMPs level of knowledge about the signs of TB and the medium through which they learned how to treat TB. A majority of TMPs acquired their knowledge on how to treat TB from their parents, relatives, and other healers. A large proportion of TMPs reported that they acquired their skills through a combination of parental and other healers' knowledge. A minority reported that they acquired the skills through books and belonging to healers associations. In fact, the only TMPs who reported that they had acquired the skills through books and healers' associations were the more educated lot. These were largely concentrated in Kenya (among the Kisii community) and Uganda among the communities around Mukono and Mayuge Districts.

Finally, the study attempted to pool together in a summary form, some of the crucial variables that influence TMPs indigenous knowledge on the management of tuberculosis using medicinal plants in the Lake Victoria region. Four variables were entered in the regression model. Table 5 contains regression coefficients and their relative order of significance in determining the TMPs knowledge about causes, signs and appropriate choice of the medicinal plants used to treat $\mathrm{TB}$, as measured by recurring number of mentions of these plants.

From Table 5 an examination of F-Value $(\mathrm{F}=40.21, \mathrm{P} \leq$ $0.05)$ indicates that the whole regression model was statistically significant in explaining variance in the TMPs knowledge of medicinal plant species used to treat TB. The value of the $\mathrm{R}^{2}$ carried in the table shows that 58.8 percent of the variance in TMPs indigenous knowledge regarding the medicinal plant species used to treat $\mathrm{TB}$ is explained collectively by the five variables considered in the study. This shows that all the five variables are collectively signi- ficant in explaining communities' knowledge regarding herbal treatment of TB.

Table 5. Regression Coefficients for the Determination of Indigenous Knowledge

\begin{tabular}{|c|c|c|c|}
\hline Selected Independent Variable & Beta ( $\beta$ ) & t-Value & Significance \\
\hline \hline Country & 0.48 & 2.0 & 0.001 \\
\hline Ethnicity (District) & 0.42 & 6.27 & 0.01 \\
\hline Sex of TMP & 0.18 & -1.87 & 0.05 \\
\hline Age of TMP & 0.04 & -0.407 & 0.05 \\
\hline Main occupation of TMP & 0.52 & 0.37 & 0.01 \\
\hline $\mathrm{R}^{2}$ & & $=0.588$ \\
\hline F- Value (P $\leq 0.05)$ & \multicolumn{3}{|c|}{$=40.21$} \\
\hline
\end{tabular}

From the t-test, it was found that all the five variables were statistically significant in explaining variance in TMPs knowledge about plant species used in the treatment of TB in the Lake Victoria region. An examination of the beta value $(\beta)$ reveals that the more crucial variables that positively influence communities' indigenous knowledge, in decreasing order of magnitude are:

Country of residence (beta $=0.48, \mathrm{P} \leq 0.001$ ); ethnicity as measured by district of origin (beta $=0.42, \mathrm{P} \leq 0.01$ ); sex of TMP $($ beta $=0.18 . \mathrm{P} \leq 0.05)$, age of the TMP $($ beta $=0.04, \mathrm{P} \leq$ 0.05 ) and main occupation (beta $=0.52, \mathrm{P} \leq 0.01$ ). The result further shows that although sex and age are crucial determinants of indigenous knowledge on herbal treatment of TB, it also had a negative impact. This negative impact implies that indigenous knowledge is being confined to the older members of the community and also to one gender (males).

\section{DISCUSSION}

This study established that there is a positive and significant correlation between the prevalence of TB (as measured by the number of patients seeking TB treatment from TMPs) and age $(r=0.58)$ at $P \leq 0.05$. It was found that $\mathrm{TB}$ was most prevalent among the middle age and older age brackets. This was in spite of efforts made to curb the spread of TB in most countries [1]. This could be attributed to the 
reactivation of the latent infections acquired many years earlier [20]. In the current study, $37.4 \%$ of the TB cases were in the middle age bracket. This trend of TB prevalence affecting middle age to old age group categories is consistent with other studies which have attributed the trend to the advent of HIV/ AIDS, which is most prevalent in people in this age brackets [2]. These sentiments are further collaborated by Kuban et al. [21] and Anyangwe et al. [1] who separately argue that TB is the most common opportunistic infection associated with HIV/AIDS, which may account for the high prevalence in the middle to old-age groups.

The current trends in the communities surveyed are that most young people are now going to school and not bothered about traditional knowledge. The practice is not respected by the high profile people in the community and mostly attracts people with low education and few livelihood options. In fact, Mbarara had the most highly trained TMPs (a nurse and a university graduate). Therefore, the fact that the majority of healers are middle aged and acquired the knowledge from relatives, is an indication that they are likely to die with their knowledge and this gives impetus to the need for documentation of the traditional knowledge for posterity. Screening and documentation of medicinal plants used traditionally in the treatment of TB gives scientific backing to the traditional knowledge that could enable it earn international recognition.

With regard to knowledge of signs and symptoms of TB, the information given by traditional healers about the correct diagnosis of tuberculosis was corroborated against a checklist of the known symptoms of TB which include fever chills, night sweats, flu-like symptoms, gastrointestinal symptoms, weight loss, loss appetite, weakness and fatigue, as early phase symptoms; and persistent cough, chest pain, coughing up bloody sputum, shortness of breath, breathing difficulty, recurring bouts of fever, weight loss and progressive shortness of breath as symptoms of chronic pulmonary tuberculosis. Although it is usually difficult to diagnose TB in early phases, there was a positive correlation between the symptoms mentioned by the traditional healers and the established symptoms of TB. However, when it comes to distinguishing between multi-drugs resistant(MDR) or extensively drug resistant (XDR) TB, it was impossible for the TMPs to tell the difference. This was understandable because, even in allopathic medicine, this has to be confirmed by advanced diagnostic tests. This further presses for the need to have the TMPs to work with conventional TB laboratories especially the area of diagnostics.

Furthermore, the survey reported that use of powder, decoctions and mixtures of plants in drug preparation, was a common practice in herbal medicine. This is analogous to combination therapy, which is now the practice of choice in allopathic medicine, especially in the management of TB under the DOTS strategy. If there was to be collaboration, the TMPs could also be incorporated in the management of the DOTS program, since patients have confidence in the TMPs. (DOTS = Directly Observed Therapy, Short course). This could greatly improve compliance. Even the practice of adding other substances, such as food supplements was in agreement with a common practice in allopathic medicine where multivitamins are added to treatment regimens especially where malnutrition is suspected.
There was a moderately positive and significant relationship between the TMPs' level of knowledge about the causes and signs of TB and the age of TMPs $(r=0.48, \mathrm{P} \leq 0.05)$. The TMPs with more appropriate knowledge were in the advanced age groups of (51-60), (61-70) and above 70 years age group. This finding is consistent with the arguments by Msuya [22] about those those who hold this useful indegenous information. In fact, one TMP from the Siaya/Bondo in the Kenya sample died after the initial survey before he could give further details.

There was no significant correlation between the knowledge of signs of TB and the source of learning of TB treatment. Most TMPs reported that they had learned how to treat TB through their parents, from relatives, through their interaction with other healers and from dreams. It was only the most educated TMPs who had learned the skills through reading books and belonging to healers associations. In fact, it was only in Uganda where most TMPs had well-established associations yet they complained that they did not share benefits from the intellectual property rights (IPR). This was making them hesitant to share their indigenous knowledge with other healers. It was also reported from Uganda that many TMPs' associations had broken away from Uganda ne Dagala Lyayo (UDL) the umbrella organization of traditional medicine practitioners in Uganda the reason being poor coordination and inability to afford benefits to the members.

The above situation not withstanding, the study revealed that there was some degree of collaboration between Traditional Medicine Practitioners (TMPs) and the conventional health workers, especially in the area of diagnosis particularly in Uganda. This is a good development and shows that advocacy towards integration of Traditional and Allopathic Medicine is moving in the right direction. The problem has been that the practitioners in conventional medicine do not want to collaborate with the TMPs, whom they regard to be very much inferior. In the post-survey workshop conducted in Uganda with the TMPs, it became very clear that the TMPs were ready to collaborate if the Government and conventional medical workers were willing to work with them. Considering the fact the practicing TMPs knew how to recognize $\mathrm{TB}$ and that traditional knowledge on curing $\mathrm{TB}$ exists, low level collaboration could even start immediately especially in the area of diagnosis and screening patients after reporting recovery. Furthermore, the fact that no rituals were reported to be involved during the administration of herbal medicine should make the herbal medicine easy to accept. There should be concern as to why people still visit TMPs for remedy against TB when there are government hospitals offering free services.

Another factor that came out clearly was that the practice of traditional medicine provides an important source of employment for the lowly educated. The TMPs employ their spouses and some other family members, and this has a bearing towards poverty alleviation. However, for this contribution to be of some significance there is need to add value to the practice and make it more attractive to the people of high profile in society. Value addition is especially necessary in the areas of providing scientific backing to the practice by screening and documenting the efficacy and safety of the herbal medicines as well standardizing the 
administration procedures and upgrading the methods of preparation and storage. This would especially help in the area of drug administration where highly variable doses were being used. Determination of MICs, MBCs safety of extracts from the medicinal plants in use could help come out with standardized doses and appropriate routes of administration. Use of animal models could help work out the toxicity/ adverse reactions and later on clinical trials could be carried out to work out standard doses. Some work in this area has already started in some countries like Myanmar where some clinical trials were conducted on some plant extracts [23].

Furthermore, low charges average for the treatment indicate that, if the traditional remedies could be found to be effective and safe to use as anti TB drugs, this would contribute a lot towards making the management of TB affordable to many. This is particularly important bearing in mind that the majority of the people in these communities live below the poverty line. In this respect, the TMPs in Tanzania were charging less compared to Kenya and Uganda. This could probably have been due to easy accessibility to free treatment of TB by the government in Tanzania.

\section{Medicinal Plant Species}

Many species have been documented in this study. We assume that species shared by many healers from more than one country have a higher probability of having activity against TB. If such species could be found to have activity it would be recommended that they are retained by the TMPs. Besides, some of the plants have already been reported to be active by some researchers, examples being Lantana camara [24] and Warburgia ugandensis [14]. Furthermore, many of the mentioned plants have already been screened for activity against various microorganisms and they have also been found to contain secondary metabolites that are known to be biologically active. Part of the information and references are summarized in Table 4. In the follow-up studies we intend to evaluate these species to determine their pharmacological activity, phytochemistry and therapeutic effects. There is potential that some of these plants could serve as sources of novel compounds for drug development.

\section{Conservation Issues}

The exploitation of naturally growing or wild plant species raises concerns about the sustainability of exploited species. Usually species that are collected from the wild, especially from common areas may become locally extinct when their habitats are destroyed or modified. This is commonly a consequence of human population growth. Sometimes the exploitation of favored species such as Warburgia ugandensis may lead to over-exploitation of the species. It is proposed that important species such as these should be domesticated. However, the domestication of naturally growing species can only be successful after a careful selection of species for which the level of investment required is commensurate to the anticipated benefits.

\section{CONCLUSION}

The results of this study clearly indicate that indigenous knowledge on treatment of TB exists in the area surveyed but with most of the practices at rudimentary stage especially in the area of preparation, standardisation, storage and preservation. It is also evident that the people in the study area did not prefer herbal medicines due to cost implications but due to the belief that they could be cured and the good rapport established between the TMPs and their patients. This study has established that there is need to enhance collaboration between the TMPs, scientists and allopathic medicine practitioners in the field of processing, packaging and preservation of herbal medicines, as well as in the diagnosis of TB. When this is coupled with mass screening of the identified plants, there is good ground to believe that this could contribute greatly to improving health care in the rural communities as well as presenting opportunities for developing new and more effective anti TB drugs that are now badly needed.

\section{RECOMMENDATIONS}

A follow-up of the TB patients has to be made to understand their attitudes towards TMPs and how they perceive the benefits of treatment. This needs to be done simultaneously with laboratory tests on medicinal plants collected from herbalists to determine their antimycobacterial activity and to isolate and characterize the compounds that actually treat tuberculosis.

\section{ACKNOWLEDGEMENTS}

This first phase of the study benefited from the generous funding from VicRes in Kampala Uganda. The researchers are genuinely grateful for the support. We also appreciate the efforts made by the respondents and research assistants who helped during the data collection exercise. We also acknowledge the authorities in the respective countries who sanctioned the survey.

\section{REFERENCES}

[1] Anyangwe INA, Akenji TN, Mbacham WF, Penlap AP, Titanji VPK. Seasonal variation and prevalence of tuberculosis among health seekers in the South Western Cameroon. East Afr Med J 2006; 588-95.

[2] WHO. What is the evidence for an association between TB and HIV. India: SEARO Publications on HIV/ AIDS 2002.

[3] WHO. Global tuberculosis control report. Geneva 2004; p. 42

[4] Eriki PP, Okwera A, Aisu T, et al. The influence of human immunodeficiency virus infection on tuberculosis in Kampala, Uganda. Am Rev Resp Dis 1991; 143: pp. 185-7.

[5] Kamuolratanakul P, Sawwert H, Kongsin S. Economic impact of tuberculosis at the household level. Int J Turbec Lung Dis 1999; 3: 596-602.

[6] Bloom M. Extensively drug resistant organism. USA: Med Page Today 2006.

[7] Thorn A. South Africa: playing catch up with XDR TB. Cape Town: Health-e-News 2006.

[8] Wright A, Bai G, Barren L, et al. Emergence of Mycobacterium tuberculosis with extensive resistance to second-line drugs. A 2000-2004 report.

[9] Centers for Disease Control (CDC). Worldwide emergence of Mycobacterium tuberculosis with extensive resistance to second line drugs. Morbid Mortal Wkly Rep 2005; 55(10).

[10] Camp R, Jeffrey R, Swan T, Syed J. What is in the pipeline: new HIV drugs, vaccines, microbicides, $\mathrm{HCV}$ and $\mathrm{TB}$ treatments in clinical trials. New York, USA: Treatment Action Group (TAG) 2005 .

[11] Orodho AJ. Elements of Education and Social Science research methods. Nairobi/ Maseno 2009; pp. 126-133. 
[12] Debella A, Olaf K, Martin GS, et al. A diterpene, a flavonol glycoside and a phytosterol from Securidaca longipendunculata and Entada abyssinica. Monatshefte Chem 2002; 131: 401-8.

[13] Xu M, Litaudon M, Krief S, et al. Ugandenial A, a new drimanetype sesquiterpenoid from Warburgia ugandensis. Molecules 2009; 14: 3844-50.

[14] Wube AA, Bucar F, Gibbons S, Asres K. Sesquiterpenes from Warburgia ugandensis and their antimycobacterial activity. Phytochemistry 2005; 66(19): 2309-15.

[15] Kannanl M, Ranjit Singh AJA, Narayanan M. Phytochemistry and Ethnopharmacological studies on Rubia cordifolia Linn. Ethnobot leaflets $2009 ; 13: 338-42$.

[16] Adeniyi BA, Odufowoke RO, Olaleye SB. The antibacterial and gastro protective properties of Eucalyptus torelliana (Myrtaceae) crude extracts. Int J Pharmacol 2006; 2: 362-5.

[17] Adeniyi BA. The phytochemical screening and antimicrobial activity of leaf extracts of Eucalyptus comadulensis and Eucalyptus torelliana. Sci Alert 2008; Available from: http:// www.scialert.net/

[18] Ollila D, Olwa-Odyek, Opuda-Osobo J. Screening extracts of Zanthoxylum chalybeum and Warburgia ugandensis for activity against measles virus (Swartz and Admonston strains) in vitro. Afr Health Sci 2002; 2(1): 2-10.
[19] Doughari JH, Manzara S. In vitro antibacterial activity of crude leaf extracts of Mangifera indica Linn. Afr J Microbiol Res 2008; 2: 067-072.

[20] Philippa JE, Gibson A, Murad S, et al. High rates of clustering of strains causing tuberculosis in Harare, Zimbabwe: a molecular epidemiological study. J Clin Microbiol 2004; 42(10): 4536-44.

[21] Kuaban C, Ndoumou A, Koulla-shiros S, Afeneze E, Ghipponi PM, Pignon D. Seroprevalence of HIV infection among patients with pulmonary tuberculosis in Yaounde, Cameroon. West Afr J Med 1995; 14: 112-5.

[22] Msuya J. Challenges and opportunities in the protection and preservation of indigenous knowledge in Africa. Int Rev Inform Ethics 2007; 7(09).

[23] Soe P, Lwin T, Lin T, Zin T, Ti T. Communicable diseases: the role of traditional medicine in treatment of multi-resistant pulmonary tuberculosis, myanmar. Region Health Forum 2006; 10 2.

[24] Kirimhuzya C, Joloba M, Waako P, Olwa-Odyek. The antimycobacterial activity of Lantana camara, a plant used traditionally to treat the symptoms of tuberculosis in South Western Uganda. Afr Health Sci 2009; 9 (1): 40-5.

[25] Orodho AJ. Techniques of writing research proposals and reports in Education and Social Sciences. Kanezja Hp Enterprises 2010; pp. $35-88$.

Received: December 07, 2010

Revised: December 28, 2010

Accepted: January 18, 2011

(C) Orodho et al.; Licensee Bentham Open.

This is an open access article licensed under the terms of the Creative Commons Attribution Non-Commercial License (http://creativecommons.org/licenses/by$\mathrm{nc} / 3.0 /$ ), which permits unrestricted, non-commercial use, distribution and reproduction in any medium, provided the work is properly cited. 